\title{
Pedagogical imagination and practical wisdom: the role of good narratives in teacher education and professional development
}

\author{
By Ruhi Tyson 201509 \\ Paper presented at ECER 2015 in Budapest in the Teacher Education network
}

\begin{abstract}
There is an increasing awareness that teaching is a practice where moral action is inseparable from pedagogical action and where wise deliberation or reflection on what course of action to take as an educator is an important part of being a good teacher. This paper will focus on rethinking the role of narratives as an articulation of such practical knowledge and the enrichment they might bring to a teacher's pedagogical imagination. Working within a conceptual framework drawing on Schön and Aristotle, the study presents a group of narratives describing successful conflict resolution told by students at a newly launched teacher education program. These are discussed as part of a teachers' practice repertoire and the argument is made that the local and personal repertoires of practitioners need to be complemented with elements from the repertoire of others, something systematic research into narratives of teaching in action can be part of.
\end{abstract}

Key words: Pedagogical imagination; Phronesis; Reflective practice; Narrative; Practical knowledge; Teacher education; Professional development

\section{Introduction}

The practice of education has been recognized as an inherently moral or ethical activity from Plato and Cicero through Rosseau and Pestalozzi. This has continued in educational research during the $20^{\text {th }}$ century and over the past three decades an extensive discussion has emerged about the practice aspects of teaching (cf. eg. Dunne, 1993; Eisner, 2002; Loughran, 2006; Shulman, 2004). In particular, there is an increasing literature recognizing this that often takes its bearings from Aristotle and his distinction between techne, the craft-like aspects of knowledge (in this case teaching, especially subject teaching), and phronesis, the intellectual virtue of practical wisdom needed in order to promote a good life in general (eg. Bondi et. al. eds., 2011; Kemmis \& Smith, 2008; Kinsella \& Pitman, 2012; Sockett, 2012). Both forms of practical knowledge are of importance for teachers in their professional activities although more often than not, phronesis is the focus of these arguments. Since phronesis is practical, ie. situational and experiential, it is open to narrative forms of articulation because narratives are capable of preserving the particularity of practice in contrast to general statements (Gallagher, 2013; Tyson, 2015a; Worth, 2008). These considerations and those of Schön (1983; 1987) on reflective practice have resulted in some insightful critiques of academic teacher training as placing too little weight on those aspects of the profession that require practice. Parallel to this, Nussbaum and others (eg. Johnson, 1993; Nussbaum, 1978, 2001) have argued for a narrative education of the moral imagination on the grounds that narratives of moral actions and situations can contribute to a person's practical wisdom because the ability to deliberate wisely on a course of action is an activity that requires imagination. Working with narratives in teacher education as a way of developing reflective practice and pedagogical content knowledge is hardly a novel idea (cf. Gudmundsdottir, 1991; Jalongo \& Isenberg, 1995; McEwan \& Egan eds., 
1995; McDrury \& Alterio, 2002; Shulman, 2004; Witherell \& Noddings eds., 1991). Nor is a focus on narrative and (moral) imagination (Gallagher, 2013; Jagla, 1992; Witherell, Tran \& Othus, 1995). But a more narrow and systematic focus where narratives are seen as expressions of practical knowledge (ie. a didactical approach) and where this in turn means that narratives of successful action are especially important to record and preserve as told is less common.

This article builds on the arguments above in order to advance a vocational, pedagogical, perspective on (moral) imagination. It makes the case for, and discusses how, narratives of teaching in action (to use a term from Schön) or what might also be termed didactical narratives can contribute to teachers' pedagogical imagination (moral imagination in an educational context, discussed further below). By taking this vocational perspective the argument is also made that techne and phronesis are fundamentally entwined in practice, which is a contributing reason for calling it pedagogical rather than moral imagination. The empirical study presented is that of a teacher education program in Sweden where the enrichment of pedagogical imagination through narratives of teaching in action has been made part of the curriculum. The ensuing discussion and conclusions point to the potential inherent in giving more systematic scholarly attention to such narratives of teaching in action as well as the importance of enriching ${ }^{1}$ the pedagogical imagination of teachers in training and in professional development. Because the subject matter outlined above is vast I will begin the argument by presenting one of the narratives from the study in order to then develop the various theoretical positions through it. This necessitates a brief introduction but has the benefit of making the following argument more transparent to the aim of the text.

\section{Telling stories of successful conflict resolution}

During the spring of 2015 an in-service teacher education program was started in one of Sweden's larger cities. The training lasts four years part-time, and most of the participants already work as teachers. This particular kind of teacher is called fritidsteacher in Sweden and works with children from grades 1-4 in after school care. The program in question has an emphasis on integrating academic studies with vocational practice, which has resulted in each semester having a defined practical focus. Thus the first, spring, semester focused on successful conflict resolution where various tasks were given during the academic sessions, which take place once a month over two days. These tasks were to be carried out at work and then brought back for shared reflection and discussion. One of them consisted in writing down a story detailing the deliberation and action of a successful conflict resolution. Here is one of those narratives.

\section{The Pocket Mirror}

At our fritids we have a boy we can call Olle. He's in third grade. He's the kind of boy that one knows is at fritids when he's there. Both teachers and children find him disturbing (he yells and makes a lot of sound) and he often disrupts activities and play through his way of being and acting. This time he had taken a small pocket mirror from a girl and refused to return it. The girl herself did not come to get me but sent another one who complained that Olle had taken the other girls pocket mirror and asked me to come help

\footnotetext{
${ }^{1}$ I use the term enrich rather than educate or develop because it seems more straightforward. Narratives of actions and deliberations that are new to us enrich our capacity to imagine possibilities. Perhaps writing stories or doing other forms of art does educate or develop one's imagination however that is a matter that lies outside of the present argument.

2 The distinction between artistry and aesthetic activity is made in different ways depending on perspective. Thus, there is an understanding of art as techne in the Aristotelian tradition that Elliot (2002) proceeds from in discussing why teaching is not just a matter of phronesis. As understood here,
} 
get it back. I went into the room close by where Olle sat followed by a tail of children who were keen on seeing what was going to happen. There was considerable tension in the air since this wasn't a unique occurrence and it's always exiting to see how we in the staff deal with such situations.

I sat down next to Olle, breathed out and said: Hi Olle! Do you like mirrors?

Olle: Yes I do.

Me: Do you have any mirrors of your own?

Olle: Yes, but it's huge. (He gets up and measures with his hands and judging by the size it must be a wall mirror)

Me: Wow, that's a large mirror!

Olle: Yes.

Me: Yes, it would look pretty funny if you came to school on your bike with that under your arm (laughing kindly).

Olle looks happy, then he gets up and gives the girl back her pocket mirror on his own accord without my saying anything more. All the children looking on seem satisfied and after that things return to normal. At the end of the day I notice that Olle once again has the girl's mirror and he notices me noticing. I don't say anything but he understands anyway that I am curious about the mirror. He says that he got it from the girl and she confirms it. She thought he could have it since he didn't have one and she had several at home.

I will now go on to consider what kind of practical knowledge is articulated in the narrative. After that I will return to the study to discuss it more extensively together with three other narratives.

\section{The narrative articulation of practical knowledge}

The story about The Pocket Mirror is a story containing an account of a teacher's observations, deliberations (the term partly overlaps with reflection) and actions. It might be worthwhile starting with what it is not. It is not a complete account of an event but a selective, and perhaps not even very accurate, one. However, the focus here is not on this particular teacher's actual knowledge and capacity but rather on what the narrative has to offer other practitioners and members of the research community. To grasp this I will draw from two perspectives: that of Schön $(1983,1987)$ and from Aristotle's philosophy (2009). Schön highlights the reflective process that needs to be educated for, especially in design-like occupations to which he counts teaching. Aristotle makes a valuable distinction between craft-like knowledge and practical wisdom that provides further clarification of what the story is about. What I will be arguing can be summarized in five steps:

1. Teaching (in the sense of pedagogical action) is a matter of propositional as well as practical knowledge and know-how.

2. The practical aspects need practice (actual or simulated).

3. This practice needs to be reflective both in the sense Schön thinks of reflective practice and in the sense of critically deliberating about what constitutes good and bad practice respectively. 
4. Skilled practice is also a matter of having the imagination needed to approach a unique situation appropriately.

5. Narratives of teachers' deliberations and actions can serve as sources for pedagogical reflection and imagination thus constituting a significant part of teachers' repertoire of practical knowledge.

\section{Design-like occupations and reflective practice}

Schön, with reference to Dewey, develops a perspective on professional knowledge as being, in part, a matter of artistry (1987:13-17). He argues that this is about learning to see, developing a professional gaze, which cannot be taught but rather needs to be coached. This seeing is a capacity to grasp something as a design-like whole, be it in architecture, in psychoanalysis or in teaching. For teachers it is about learning to see a situation as a pedagogical situation and to act within it with respect to it as a totality analogous to how an artist needs to be able to grasp or perceive a work of art in its totality. Part of this is also the development of a capacity for reflective practice, which Schön differentiates in two ways: reflection in action and reflection on action. A skilled practitioner has an artistry that allows for reflection in the course of an action when surprises are encountered. Central to the present argument is a passage in which Schön suggests that Quist, one of the architects from a case he discusses, has (1987:66 italics in original):

[B]uilt up a repertoire of examples, images, understandings, and actions. His repertoire ranges across the design domains. It includes sites he has seen, buildings he has known, design problems he has encountered, and solutions he has devised. All these things are part of Quist's repertoire insofar as they are accessible to him for understanding and action.

When a practitioner makes sense of a situation he perceives to be unique, he sees it as something already present in his repertoire. To see this site as that one is not to subsume the first under a familiar category or rule. It is rather, to see the unfamiliar situation as both similar to and different from the familiar one[.]

The story about the pocket mirror, I suggest, has the potential to be part of such a repertoire and not just the repertoire of the narrator but also that of others. Furthermore, given that teaching to such a significant degree is a matter of human interaction, a teacher's repertoire consists largely of such stories either articulated and remembered or subsumed into a body of non-verbalized experience. One of the main points of the present argument is that the local and personal repertoires of practitioners need to be complemented with elements from the repertoire of others.

The seeing that Schön writes of, seeing this as that, accurately describes the act of imagination as understood here. He doesn't use the term imagination himself, writing instead of interpretation (1987:228f) and the capacity to reinterpret what one sees or hears. The difference is that Schön writes of the process and results whereas the term imagination corresponds to the present focus on the activity of the teacher. The Pocket Mirror presents one with a description of pedagogical imagination and action. The reader in turn needs to apply pedagogical imagination in turning from this the particularity of the story) to a potential that (reframing it to draw on it in another more or less similar situation). The risk is always twofold, either being too literal or too arbitrary. Becoming arbitrary suggests a distinction made already by Novalis, Schiller and Schelling between imagination and fantasy. The former remains faithful to a subject whereas the latter allows itself to be arbitrary in its interpretations (Noel, 1999a:280f; Ramey, 2012:108f). Thus literalness and fantasy stand as the two excesses or extremes between which imagination balances. Finally, and as Schön intimates when choosing terms such as professional artistry and design-like occupations, imagination is at the 
center of aesthetic activity. ${ }^{2}$ Teaching, as a matter of practical knowledge requiring imagination is an artistic practice when viewed from this perspective (cf. Elliot, 2002).

Teaching as professional artistry means that there is a significant aspect of it that involves aesthetic perception, deliberation and judgment, both in immediate situations and in the composition of lessons and curricula. With aesthetic perception I mean the above-mentioned seeing this as that, ie. a kind of perception of the world that is imbued with imagination (cf. Noel, 1999a:280f., who calls it discernment). As Heron \& Reason (1997) point out this kind of perception is needed in a more fundamental way when we order the multitude of sense-impressions into a coherent whole and decide upon what to attend to and what to leave in the background. Aesthetic judgment is part of aesthetic perception but calls our attention to the more active aspect of it. Once again following Novalis, Schiller and Schelling one might call it an active imagination (cf. Ramey 2012:108f). It is a matter of aesthetic judgment when to intervene as a teacher in a process, something that is seldom a matter of outright rational thought but more of sensing or feeling a situation. In The Pocket Mirror this aesthetic judgment follows from the perception of the situation and is briefly indicated in the "drawing a deep breath", where perception moves into judgment and a brief deliberation before moving into action (asking: you like mirrors don't you?). Aesthetic deliberation then, is understood here as a more prolonged process of aesthetic judgment potentially including a more articulated reflective component, either in-action or on-action. These three seldom appear clearly separate from each other so that it is mostly a matter of supporting analysis and intellectual discernment to make the distinctions.

Thus, to summarize:

Imagination in action can be differentiated as, but not limited to

Aesthetic perception/discernment

Aesthetic judgment

Aesthetic deliberation

By making these differentiations it is easier to think in a nuanced way about the complex activity that the practice of teaching entails. They are also important to bear in mind because the discussion of practical wisdom (phronesis) to which I will turn next contains different interpretations sometimes emphasizing one or the other aspect (cf. Noel, 1999a).

\section{Aristotle and the distinction between craft-like knowledge and practical wisdom}

Aristotle (2009) provides us with a useful distinction between craft-like practical knowledge (techne) and prudence or practical wisdom (phronesis). Both of these are practical. First, in that they require practice and experience to develop. Second, in that the practical is situational, local and context-bound. Whereas craft-like knowledge is focused on making things in a very wide sense including medicine or subject teaching, practical wisdom is about deliberating (or as I will be writing from hereon, imagining) well about the right course of action in order to promote human flourishing

\footnotetext{
${ }^{2}$ The distinction between artistry and aesthetic activity is made in different ways depending on perspective. Thus, there is an understanding of art as techne in the Aristotelian tradition that Elliot (2002) proceeds from in discussing why teaching is not just a matter of phronesis. As understood here, aesthetic activity more or less overlaps with artistry and is part of both techne and phronesis. Imagination is a central aspect of aesthetic activity but not an exclusive one. A full argument about aesthetic activity is neither possible nor required here but would proceed from Schiller (cf. Schiller, 2010; Tyson, 2014, 2015b).
} 
(eudaimonia) or the good life in general (cf. eg. Biesta, 2015; Campbell, 2013; Curren, 2008). Aristotle calls acting virtuously praxis meaning that he differentiates between, for example, wisely judging when and how to act tactfully (to use a teacher virtue described by van Manen, 1991) and the actual act together with the capacity to be tactful. This is important because the narrative articulation of teaching in action has the potential to enrich phronesis but not praxis. Tactfulness does not increase by other means than practicing tact. However a story about tactful action might inform a person's wise imagination so that a tactful action is carried out with greater prudence.

An important issue to address is Aristotle's argument that phronesis is something that can only develop with age, youth and practical wisdom being mutually exclusive since wisdom relies on extensive experience (cf. Elliot, 2002). Aristotle's point is well made but one of the assumptions here is that we can circumvent this to some degree through narratives. Thus, a narrative approach to these issues is perhaps especially important when students at teacher education programs are comparatively young and thus inexperienced. Stories, by remaining situational, mimic experience and can perhaps, in part, alleviate this.

The Pocket Mirror is primarily a narrative about educational phronesis. It also involves, I would argue, some amount of praxis or virtue in the pedagogical action that the teacher engages in after taking the deep breath. But the praxis aspect is important here not on account of its relative veracity but rather because descriptions of praxis transform into sources of phronesis as pedagogical imagination. It does need emphasis that the situation is a formal educational one and thus even though the craft-like (techne) aspect of the teacher's action is mostly tacit it is nevertheless there. This becomes clearer if we return to the initial point that it is not a story meant to reflect on this particular teacher's capacity but rather one meant to offer us some practical knowledge. Even though it may be relevant in a general way for those interested in expanding their repertoire of conflict resolution imagination it is clearly a vocational story, ie. its content is most relevant to teachers working in similar contexts. For a high school teacher, a teacher of apprentices or a teacher of foreign languages in grades 3-6 this might be a comparatively irrelevant narrative.

The conceptual similarity between phronesis and imagination takes the previous aesthetic distinctions one step further. Phronesis is what imagination can be called when directed towards issues of human flourishing or, in educational contexts, Bildung (cf. Tyson, 2014). This could be viewed as moving away from what Aristotle meant, especially those interpretations of him that understand deliberation as close to logical reasoning but there are alternative interpretations where phronesis and imagination (phantasia) are more clearly linked (cf. Noel, 1999b). Rather than argue back and forth on this matter I think the narrative discussed gets to the heart of it. Either such narratives can enrich practical wisdom in which case imagination is part of it or they cannot in which case I am wrong. Pedagogical imagination and phronesis meet when the teacher deals with issues of promoting the good of students something that cannot be subsumed into a craft-like focus on subject teaching. This is why Aristotle is still relevant, his distinction between techne and phronesis serves to draw our attention to two basically different modes of teaching that, although entwined, have two aims. The goal of techne is extrinsic, teaching mathematics leading to an increase in understanding of the students etc. The goal of phronesis is intrinsic: human flourishing. The value of Bildung is not first and foremost anything other than becoming gebildet. The value of wise imagination as in the narrative about the pocket mirror is in the flourishing it contributes to.

If I have emphasized the practical aspect of phronesis above, something must now be said about wisdom. It is easy to forget that moral and pedagogical action also benefit 
from a well-developed conceptual basis. In The Pocket Mirror this is not articulated explicitly but the conceptual context was Marshall Rosenberg's Non-violent communication (Rosenberg, 2003), which contains some elaborate concepts on how to deal with conflicts. However, having the general concepts provides no clue as to how they relate to the particular situation. This returns us to pedagogical imagination as the bridge teachers construct between theory and practice or from one practice situation to another. The risk with remaining entirely on the side of experience and discarding work with conceptual frameworks is at least threefold:

- First, a lack of critical awareness, ie. a naïve approach to practice.

- Second, a lack of broad horizons, ie. a narrow view of practice.

- Third, a lack of clarity in analyzing experiences.

Even though much of this can be handled through well-chosen examples these examples cannot be chosen unless a concept is there to orient one's choice.

At this point the conceptual argument can be brought to a close by characterizing what a narrative of teaching in action is. Such stories need to contain descriptions of observations, judgments, deliberations and actions (although not necessarily all in the same story) and the process connected with this. In the narratives presented here I have limited this to those that focus on one self-contained episode. However, on the other end of the spectrum one can find such narratives in biographical studies (Tyson, 2014, $2015 \mathrm{a}, 2015 \mathrm{~b}$ ) and in descriptions that fall somewhere in between (Tyson, forthcoming). In a continental European context these could well be termed didaktik-narratives (Westbury, et. al. eds., 2000). In a US context they are close to narrative articulations of pedagogical content knowledge (Shulman, 2004) and perhaps even more so to the studies of teacher lore that have been proposed (Schubert \& Ayers eds., 1992). But it would take me beyond the confines of this paper to pursue the commonalities and differences. Having characterized what a narrative of teaching in action is conceptually it is now time to turn to those more immediate considerations that went into designing the teacher education program.

\section{Designing the teacher education program}

There were several interlinked considerations that went into the design of the practiceoriented curriculum from which the introductory story was taken.

First, a solid conceptual, propositional, development is needed both of the practice-field to be explored and more generally of the constituents of practical knowledge. In the present case, as mentioned, the conceptual work was related to Marshall Rosenberg's non-violent communication method (Rosenberg, 2003). The concepts of practical knowledge and pedagogical imagination delineated above were also briefly discussed with the students.

Second, a successive training in narrative articulation is necessary. This initial project demonstrated clearly enough the wide disparity among a group of about 30 students with regards to this, leading to many narratives being too general or too short to be useful sources of imagination. This was also a matter of how we formulated the tasks where most of the useful narratives came from the first one carried out between our initial two-day session and our second. The one given to complete between the second and third proved to be more difficult to translate into action in practice leading in turn to fewer meaningful narratives. To deal with the issue of how to think and write narratively training in narrative articulation has been made an explicit course in the curriculum and is also understood in terms of practice throughout the program as the students go on writing about their experience in narrative form and reflecting together on it. 
Third, and most importantly, the narratives need to be narratives of unusual success not of rote practice, failure or simply formulations of common problems, which is a take on Schön's argument (1987:13) that: "we can learn a great deal ... by carefully studying the performance of unusually competent performers". In a sense the successful outliers provide far more substance than the average stories do. This is not only relevant in the development of a rich pedagogical imagination but also if one is striving to systematically map and analyze a field of practical knowledge (discussed further in Tyson forthcoming). From a practitioner standpoint unusually successful narratives are also able to serve as so-called black swans (Larsson, 2009) in that they help falsify premises taken for granted. Thus on the subject of conflict resolution narratives such as The Pocket Mirror can help falsify a number of common-sense premises related to crime, punishment and moralizing judgment. Stories of failures and unsolved problems and the reflection that can develop from them can certainly be sources of education and they are often at the center of case-based curricula. But here a distinction must be made between techne and phronesis since both are forms of practical knowledge that can be narratively articulated. When teaching in action is mainly a matter of techne, ie. for example subject teaching or managing a process of play, the situation is not always so obviously charged with matters pertaining to flourishing. When focusing on this in teacher education it is less important to insist on unusual success although it can still be relevant. It is when the focus shifts towards those aspects of teaching that require phronesis as well as techne such as conflict resolution or, more broadly speaking, Bildung (cf. Tyson, 2015b), that it becomes important to pay attention to the success aspect. The assumption in the program is that given enough time between sessions, in this case about three weeks, most practitioners will end up with examples of unusually competent performance in conflict resolution worth discussing. The program is too new for there to be even indications regarding this assumption for the time being, especially since not all of the participants are fluent in articulating their actions narratively. Finally, it is also an ethical matter when it comes to sensitive subjects such as conflicts. Presenting stories, especially ones in which children are involved, to a larger public asks for some reflection on what we tell each other and here stories that are about successful practice do not impose as much on the integrity of the participants.

Finally, on a general note, we need to consider the environment in which a curriculum is created and which it provides, in turn, to practitioners. Fritids is a less regulated environment than school and thus the creation of a curriculum for it faces fewer constraints. Depending on regulations and policies some teacher education curricula may be far more difficult to shape according to the principles discussed here. The other side of this is that many practitioners are faced with institutional practices, local curricula, etc. that are not conducive to narratives of Bildung. To discuss this extensively would take me beyond the confines of this article but it can at least be acknowledged that the environments in which these stories have developed are all generally supportive of this kind of conflict-resolution.

\section{The study}

The study presents a selection of narratives from the first three sessions of the newly launched after school care teacher (fritidslärare) training program mentioned earlier. Because of its recent start the number of participants fluctuated somewhat but can be placed at between 25-30, meeting for two days each month. Between these meetings most of the participants already worked as after school care (hereafter called fritids) teachers and were thus in an excellent position to practice during that time and then reflect on this practice during the sessions.

The Pocket Mirror is contrasted here with three other narratives that present variations on conflict resolution situations in the fritids-context. They are a selection from about a 
dozen or so. The number is difficult to pin down since several of the narratives were only partially descriptive or perhaps too obscure to be taken out of their context. Thus, of the remaining, unpublished narratives, another four seem suitable for publication. I have translated the present ones from Swedish and made minor changes when needed to preserve anonymity or when they veered from narrative to discursive language but apart from this they are as they were. All of the teacher-students have given their consent for the narratives to be used in the present research context.

\section{The Ball}

At one point a group of girls turned to a teacher at fritids for assistance with a disagreement they had. One of them had become excluded from their play. The teacher had the impression they wanted to continue playing together but couldn't figure out how to become one group again. He first listened to the group of girls and then to the girl who was unhappy. The girl who was unhappy was disagreeing with the others on the rules that were to structure their improvised play.

The teacher expressed to them that it was good that they had sought the help of an adult but also that it is often good to find ones own solutions to problems. He said that he thought the girls could handle the situation by themselves this time.

He asked if they had any suggestions on how to get that feel out of oneself that appears in ones stomach when there is dissent and one girl suggested that one might kick a football back and forth in the group. The teacher gave the girls a football and promised to come back in a little while in case they needed him. When he returned a few minutes later the ball lay on the ground but the girls had returned to the scene of their previous play. They had solved their conflict among themselves and during the break for a snack the girls were positive and there was harmony in the group.

\section{Field-hockey and Cover Pants}

I had been to the classroom to get the children that were going to fritids. Before the group left the classroom I reminded them that we would be outside before snack-time and that they needed thick cover-pants over their regular ones because it had rained recently and was wet outside.

One by one they left the corridor and went out to wait outside where my colleague was. Finally there was just one boy left who, looking sour, came up to me and said: "I refuse to wear these cover-pants! They suck!" I answered: "can you explain so that I understand." "Yes, it's so darned difficult and takes so much time to get all these clothes on. I'm just gonna play field-hockey and not be in the sandbox," he said.

"Ok, then I understand you, but you know, even if you're not gonna be in the sandbox or close to the stream there are pools of water almost everywhere. On the field-hockey court there's a large pool of water and more often than not you guys have to shovel the water off the court before playing."

The boy didn't answer but began rummaging around in his bag. "Yes, but are the large shovels out so we can shovel?" he said and continued rummaging. "If they're not out we can get them in the recycling house," I answered.

I began putting my boots on by the door when the boy said: "you can go ahead with the others to fritids, I'll come when I'm finished."

"Ok I'll go then," I said. When we got down to fritids and the kids had left their bags inside and were on their way out again the boy came running. He called: "look I'm here 
now and I put the cover-pants on, 'cause you know, if I'm gonna play goalie I'll be sitting on my knees and then my new pants will get wet."

"Do you have new pants?" I asked. "Yes, and a new sweater, do you wanna see?" "Of course," I answered. The boy pulled the zipper down on his jacket and showed me the sweater. It looked good. "And I can see that you're wearing the cover-pants, that's good 'cause now you won't get wet," I said.

Earlier this winter he would scream and get angry when told to wear covers or thermal pants. And it didn't get much better when I told him he had to. Now, a few times when I've encountered resistance from him I've asked him to explain why he's angry and resists. This has significantly improved things. The day before Easter vacation he put on the covers without my having said anything at all. Then he walked up to me and said: "there was a bit of rain earlier today when we had math class." I told him that I'd noticed too so I was wearing my own covers. He smiled and walked out to the others.

\section{Playing War}

A game that was initially fun, "Indians and cowboys," degenerates into "real war." A gang of first graders feels they need to fortify themselves and they arm themselves with stones, sticks and nails. The other gang consists of kids from second and third grade who still believe they are just playing. One of them comes running to fetch me. They've been caught by a hail of stones and one of them has gotten a larger one on the head. Another has gotten hit across the stomach with a stick. I myself end up in the line of fire like a barrier between the two camps and I gather myself and instead of barking at them angrily I find a white (luckily) handkerchief in my pocket and wave it around calling for "Peace!" The attack ceases immediately and I say:

"Oh dear, many dead here! It looks really bad. We need a ceasefire."

This brings both gangs out to the wounded and they start making peace with each other. The process isn't without its difficulties. But with almost no help from me they manage to decide together that it's best to stop playing war if it leads to people getting injured. The older children explain very pedagogically that it is never real war when kids play.

I don't admonish anyone, limiting myself to asking, when the older children ask me if it's forbidden here at fritids to play war:

"What do you think?" They all come to an agreement that it is forbidden.

Later the one who threw the rock told his mother what had happened. He receives some help from me but wants to tell her himself. Mother wants to admonish. I ask her to wait. The boy begins drawing a soldier with weapons in his hands in the gravel and says:

"Play war? Yes! Real war? No!" And then he crosses his picture over with two strokes.

Later he tells me that the army has held military exercises for several days outside of his window and that he's been awake during the night.

\section{Discussion}

One issue worth considering directly is what happens when narratives such as these are removed from their institutional and cultural context as well as from their mostly oral and personal form and changed into a written and impersonal one. There is a need to be aware of these issues both when doing research and as practitioner and to consider when narratives can be presented in written form outside of their immediate context. 
One aspect of this is the development of a conceptual context that can support the lack of situational context, which contributes to why the initial considerations on practical knowledge etc. are important. Another is having a subsequent discussion among participating practitioners regarding the narratives and what they are about, how they can enrich a persons' pedagogical imagination. Apart from this practice-related approach a similar reflection on what these narratives offer is needed from a more scholarly perspective, which is what I have attempted, however briefly, in the following. This is not to be confused with an analysis, the aim here being to establish a framework for understanding these narratives as sources of knowledge.

The narratives presented here have three things in common. They are all taken from the same vocational context, they all center on descriptions of brief episodes and they are all potential sources of pedagogical imagination. These three similarities are relevant. First, because, as mentioned, another vocational context say, a master-apprentice relationship, will yield other kinds of narratives (cf. Tyson, 2015a for an example of such masterapprentice stories). Second, because there are other kinds of narratives than the episodic, specifically larger biographical ones (cf. Tyson, 2015b) as well as less elaborate Bildung-oriented ones (discussed more extensively in Tyson, forthcoming). Third, they constitute variations on a specific theme of pedagogical-moral imagination, one that might be termed a non-interventional and non-judgmental approach to dealing with conflicts (in this case as described by Rosenberg, 2003). With non-judgmental I mean that none of the teachers use language and actions that confront the children with being right or wrong morally speaking. With non-intervention I mean that the teachers do not approach the problem head-on but instead try to find ways where doing something less confrontational will lead to changes in the actual conflict as well.

The Pocket Mirror is perhaps the most obvious, instead of scolding the boy or otherwise forcing him to face the actual problem directly, the teacher attends to the boy's interest in mirrors, allows him to work through his action on his own and opens a space where he can do this without feeling threatened. In this case in the presence of the other children and because of this they also become aware of something he is feeling which in turn opens a space for the girl from whom the mirror was taken to act generously and gift it to him.

The Ball is a very brief narrative, perhaps too brief to be a significant part of the repertoire of other practitioners taken out of context. It could be interpreted as just another case of a teacher, pressed for time, not really getting involved in the process but leaving it to the students. This is belied by the conversation where the teacher is involved to the point where a concrete suggestion of how to solve the issue is worked out (kicking the ball). In the context of non-intervention, the teacher helps the children focus on the ball as a way of dealing with their emotional discomfort. I assume here that the main problem for them wasn't how to solve the conflict intellectually but how to deal with the emotional discord it had introduced.

Field-hockey and Cover Pants is a narrative that, taken out of context, can be interpreted as clever manipulation of the child by the adult just as well as a dialogue filled with empathy. As such it highlights a significant issue with articulating this kind of practical knowledge, it's unavoidably part of a power/knowledge nexus that cannot just be assumed to be for the good. On the other hand, by surfacing vocational narratives connected to flourishing in education (be it conflict resolution, Bildung, etc.) it becomes possible to discuss issues of power in closer relation to practice. This is especially relevant in relation to practice when it is considered successful given that it is comparatively easy to be aware of troubled practices but much less obvious to reflect critically on power-relationships in practice deemed successful or ideal. 
In Playing War, the teacher provides a clear description of intervening in a play-activity within the framework of that activity instead of immediately trying to force the children out of their imagined reality. Of the four narratives it most clearly intersects with the craft-like (techne) aspect of pedagogical knowledge: that of interacting with children as they are playing. Thus it can be a source of pedagogical imagination within this field as well. Here it is perhaps most apparent that the craft-like aspect, organizing a play-event, intersects with a phronesis-aspect, imagining wisely how to intervene in order to support a beneficial conflict resolution. In the present story the latter, practical wisdom, takes precedence owing to the situation. However, this would not have been the case if the story had centered on a situation where children were playing and were perceived to need some assistance in developing their play. Then the craft-like aspect, perhaps one might term it practical imagination, would come to the fore and wise imagination, while still present, would maybe be less central.

None of this means that what the teachers did would be wise in all similar situations (or that we can say that it actually was in practice) and some of the capacity needed to understand that can only arise through repeated practice and experience. But practice and experience do not automatically lead to wiser imagination, the capacity to perceive a situation with imagination needs to be cultivated actively and narratives hold the potential to be a significant source of pedagogical imagination; these ones within the vocational context of fritids and, I presume, similar ones such as kindergarden.

A point to bear in mind is also the difference between beginner and experienced practitioner. Narratives as examples are more effective for experienced practitioners who do not run the same risk as beginners of taking them at face value, ie. as sources of rules to follow rather than as sources of imagination. This is why teacher education institutions need to focus more on presenting students with a wider variety of narratives that explore different ways of dealing with similar situations successfully. We are brought back here to the need for a broad repertoire of stories about various aspects of the practice of teaching. Some very difficult matters to explore in the subject-area of conflict resolution for instance, are parent-teacher conflicts and conflicts among coworkers. In both cases discussing such issues on a general, propositional level, perhaps with a pair of good examples thrown in to make it more concrete is not only insufficient but really ignores the central demand on the teacher, namely taking these concepts and imagining how to actualize them in a particular situation. In this sense the narratives presented here from the pilot study are just as limited by being so few in number and serve more to illustrate and exemplify the argument than to offer a full validation of it. They also constitute one very specific kind of didactical narrative by being part of an explicit task to focus on successful non-violent conflict resolution. At the other end of the spectrum where the researcher is not so strongly present in directing the inquiry and action of the people involved we can find biographical Bildung narratives that relate to more general and vague questions such as: what do you remember that made a strong impression on you during your education? I have discussed these variations in relation to the questions posed more extensively in Tyson (forthcoming).

\section{Conclusions}

Systematic research into, and collection of, vocational narratives of teaching in action has the potential to successively widen what teachers can imagine. Given that a practitioner is limited by cultural and institutional habits with regards to her or his imagination this is important. Some ways of imagining conflict resolution might be more clearly available in certain environments rather than others. My argument here is that academic research could do much to document how teachers narrate their process of imagining practice in order to provide teachers and students with expansive perspectives on practice. The four narratives presented here, although variations on the 
theme of non-violent conflict resolution still represent four different areas of vocational practice at fritids: conflicts in play-activities, in relation to possessions or toys and in relation to common activities such as putting on clothes or eating (an area that can thus be further subdivided). Each of these practice-fields holds the potential to develop its own cluster of significant vocational narrative knowledge as the stories from the study represent didactical strategies that can be enriched through variation. Furthermore, non-violent communication is just one of several ways in thinking or theorizing about conflict. What would comparative narratives look like in significantly different theoretical environments? Given the wide variety of combinations of teaching as a craftlike activity involving practical imagination (techne) and teaching as an activity aiming at flourishing/Bildung involving wise imagination (phronesis), this kind of work is hardly begun in a systematic fashion. This could also be one way of empirically demonstrating that when it comes to pedagogical practice there isn't one identifiable best practice but rather a plethora of best practices that cannot be pinned down but only continuously revised, perhaps leading us in time to talk rather of rich practice or the like. At the same time it allows for comparison between local practices and the formation of judgments regarding the relative value on one compared to another as practiced rather than the pitting of theory against theory. It may well be that further research will show that certain conceptual frameworks are, generally speaking, richer sources of pedagogical imagination but this would require a great deal of comparative narrative studies.

Finally: teacher education programs and programs for further professional development need to include practice in narrating experience so that teachers become used to speaking and writing about their pedagogical imagination and action in the form of relevant stories. They also need to take seriously the need for enriching their students' imagination and aesthetic capacity, through storytelling but also other artistic activities. Until more research is capable of providing us with specific answers to how, and what kinds of, artistic activities enrich our pedagogical imagination, the best course of action might be to engage in several in order that individual differences among students are taken into consideration. By this I mean that it is hardly reasonable to assume that aesthetic imagination in general, ie. appreciating and/or engaging in sculpture, music, painting, etc., is something fundamentally different than pedagogical imagination. Nor is it reasonable to assume that they are essentially the same and that it is thereby sufficient to engage teacher students in say, music, for it to effect their pedagogical imagination. Rather, it seems reasonable to tentatively conclude that teacher education including practice with both the arts and with the specifics of vocational narratives is where we can expect pedagogical imagination to be enriched expansively.

\section{References:}

Aristotle. (2009). The Nichomachean ethics. Oxford: Oxford University Press.

Biesta, G. (2015). How does a competent teacher become a good teacher? On judgement, wisdom and virtuosity in teaching and teacher education, in R. Heilbronn \& L. Foreman-Peck (Eds.), Philosophical perspectives on the future of teacher education. Oxford: Wiley Blackwell.

Bondi, L. et al. eds. (2011). Towards professional wisdom. Practical deliberation in the people professions. Burlington: Ashgate.

Campbell, E. (2013). The virtuous, wise and knowledgeable teacher: living the good life as a professional practitioner, Educational Theory, 63(4), 413-429.

Carr, D. (2006). Professional and personal values and virtues in teaching and education, Oxford Review of Education, 32(2), 171-183.

Carr, D. (2003). Rival conceptions of practice in education and teaching, Journal of Philosophy of Education, 37(2), 253-266.

Connelly, F. M. \& Clandinin, D. J. (1990). Stories of experience and narrative inquiry, Educational Researcher, 19(5), 2-14.

Connelly, F. M. \& Clandinin, D. J. (1995). Narrative and education, Teachers and Teaching: Theory and Practice, 1(1), 73-85. 
Curren, R. (2008). Cardinal virtues of academic administration, Theory and Research in Education, $6(3), 337-363$.

Dunne, J. (1993). Back to the rough ground. Practical judgment and the lure of technique. Notre Dame: University of Notre Dame Press.

Eisner, E. (2002). From episteme to phronesis to artistry in the study and improvement of teaching. Teaching and Teacher Education, 18() 375-385.

Gallagher, S. (2013). An education in narratives, Educational Philosophy and Theory, 2013 1-10.

Gudmundsdottir, S. (1991). Story-maker, story-teller: narrative structures in curriculum, Journal of Curriculum Studies, 23(3), 207-218.

Heron, J. \& Reason, P. (1997). A participatory inquiry paradigm, Qualitative Inquiry 3(3), 274-295.

Jagla, V. (1992). Teachers' everyday imagination and intuition, in Schubert, W. \& Ayers, W. eds. Teacher lore. Learning from our own experience. New York: Longman.

Jalongo, M. \& Isenberg, J. (1995). Teachers' stories. From personal narrative to professional insight. San Francisco: Jossey-Bass Publishers.

Johnson, M. (1993). Moral imagination. Implications of cognitive science for ethics. Chicago: University of Chicago Press.

Kemmis, S. \& Smith, T. Eds. (2007). Enabling praxis: Challenges for education. Rotterdam: Sense Publishers.

Kinsella, E. \& Pitman, A. eds. (2012). Phronesis as professional knowledge. Practical wisdom in the professions. Rotterdam: Sense Publishers.

Larsson, S. (2009). A pluralist view of generalization in qualitative research, International Journal of Research \& Method in Education, 32(1), 25-38.

Loughran, J. (2006). Developing a pedagogy of teacher education : understanding teaching and learning about teaching. London; New York: Routledge.

McDrury, J. \& Alterio, M. (2002). Learning through storytelling in higher education. Using reflection \& experience to improve learning. London: Kogan Page.

McEwan, H. \& Egan, K. eds. (1995). Narrative in teaching, learning, and research. New York: Teacher College Press.

Noel, J. (1999a). On the varieties of phronesis, Educational Philosophy and Theory, 31(3), 273-289.

Noel, J. (1999b). Phronesis and Phantasia: Teaching with wisdom and imagination, Journal of Philosophy of Education, 33(2), 277-286.

Nussbaum, M. (2001). Upheavals of thought: The intelligence of the emotions. Cambridge: Cambridge University Press.

Ramey, J. (2012). The hermetic Deleuze. Philosophy and spiritual ordeal. Durham: Duke University Press.

Rosenberg. M. (2003). Life-enriching education. Encinitas: Puddle Dancer Press.

Schiller, F. (2010 [1795]). Über die ästethische Erziehung des Menschen. Stuttgart: Reclam.

Schön, D. (1987). Educating the reflective practitioner. San Francisco: Jossey-Bass Publishers.

Schön, D. (1983). The reflective practitioner. Basic Books.

Schubert, W. \& Ayers, W. eds. (1992). Teacher lore. Learning from our own experience. New York: Longman.

Shulman, L. S. (2004). The wisdom of practice : essays on teaching, learning, and learning to teach (1st ed.). San Francisco: Jossey-Bass.

Sockett, H. (2012). Knowledge and virtue in teaching and learning. New York: Routledge.

Tyson, R. (forthcoming). Narratives in professional development: a practical Bildung perspective.

Tyson, R. (2015a). Educating for vocational excellence: the auto/biographical exploration of enacted craft pedagogy. Vocations and learning. 8(2), 229-245.

Tyson, R. (2015b). Vocational Bildung in action. Licentiate thesis, Stockholm University Department of Education.

Tyson, R. (2014). Aesthetic Bildung in vocational education: The biographical case of bookbinding master Wolfgang B. and his apprenticeship, Vocations and learning 7(3), 345-364.

van Manen, M. (1991). Can teaching be taught? or: are real teachers found or made?, Phenomenology + Pedagogy Vol. 9.

Westbury, I. et. al. eds. (2000). Teaching as a reflective practice. The German didaktik tradition. London: Lawrence Erlbaum Associates.

Witherell, C. \& Noddings, N. eds. (1991). Stories lives tell. Narrative and dialogue in education. New York: Teachers College Press.

Witherell, C., Tran, H., Othus, J. (1995). Narrative landscapes and the moral imagination: taking the story to heart, in McEwan, H. \& Egan, K. eds. (1995). Narrative in teaching, learning, and research. New York: Teachers College Press.

Worth, S. (2008). Storytelling and narrative knowing: an examination of the epistemic benefits of welltold stories, Journal of Aesthetic Education, 42(3), 42-56. 
